\section{Commentary: Successful pairing of the Norwood and bidirectional Glenn in select older infants}

\author{
Joseph B. Clark, MD
}

In the stepwise palliation of single ventricle disease with systemic obstruction, the Norwood operation is typically performed in the first week of life and followed at 3 to 6 months by superior cavopulmonary connection. The optimal timing of the staged operations has been extensively studied and has shaped current practice. ${ }^{1,2}$ Nevertheless, there may be the rare occasion when a patient presents unusually late and needs a Norwood operation. This scenario was recently described in a large series from Saudi Arabia in which patients underwent delayed Norwood surgery. ${ }^{3}$ Although pulmonary blood flow was routinely accomplished with a Blalock-Taussig shunt or Sano conduit, 7 patients were successfully managed with a cavopulmonary shunt (CPS) (ie, bidirectional Glenn).

Elmahrouk and colleagues ${ }^{4}$ present an expanded series of 16 patients treated with combined Norwood CPS at a mean age of 138 days. No patient had prior intervention and all had evidence of increased pulmonary blood flow. Cardiac catheterization was performed in the majority and showed severe pulmonary overcirculation with increased but reversible pulmonary vascular resistance. Not unexpectedly, postoperative CPS pressures were elevated (mean $20 \mathrm{~mm} \mathrm{Hg}$ ) compared with other reports. ${ }^{5}$ Inhaled nitric oxide was used to manage postoperative pulmonary hypertension, but the effectiveness was not detailed. Previously, inhaled nitric oxide has shown variable efficacy at decreasing CPS pressures and improving oxygenation. ${ }^{6,7}$ Of the 2 hospital

\footnotetext{
From the Division of Pediatric Cardiac Surgery, Department of Pediatrics, Penn State Health Children's Hospital, Hershey, Pa.

Disclosures: The author reported no conflicts of interest.

The Journal policy requires editors and reviewers to disclose conflicts of interest and to decline handling or reviewing manuscripts for which they may have a conflict of interest. The editors and reviewers of this article have no conflicts of interest.

Received for publication Oct 28, 2021; revisions received Oct 28, 2021; accepted for publication Oct 29, 2021; available ahead of print Nov 4, 2021.

Address for reprints: Joseph B. Clark, MD, Division of Pediatric Cardiac Surgery, Department of Pediatrics, Penn State Health Children's Hospital, 500 University

Dr, H085, Hershey, PA 17033 (E-mail: jclark7@pennstatehealth.psu.edu).

J Thorac Cardiovasc Surg 2022;163:1601-2

$0022-5223 / \$ 36.00$

Copyright (c) 2021 by The American Association for Thoracic Surgery

https://doi.org/10.1016/j.jtcvs.2021.10.049
}

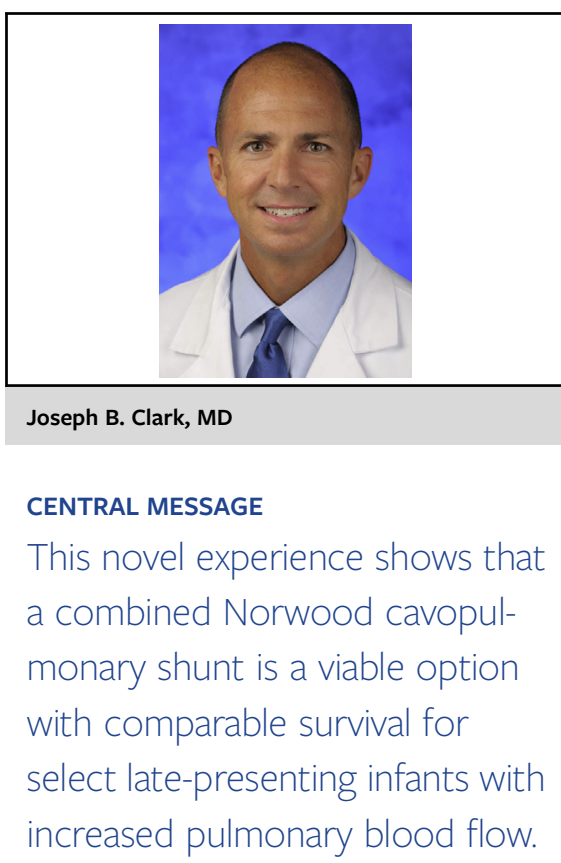

deaths, one occurred in the oldest patient (366 days) with the highest pulmonary vascular resistance $\left(3.5 \mathrm{WU} / \mathrm{m}^{2}\right.$ on $100 \%$ oxygen) who died from pulmonary hypertensive crisis on the second day. Given this outcome, the authors recommend an upper threshold of $2.5 \mathrm{WU} / \mathrm{m}^{2}$ on $100 \%$ oxygen for Norwood CPS.

As the authors comment, hospital mortality in this series $(12.5 \%)$ mirrored the comprehensive stage 2 operation $(12.4 \%)$ in the hybrid pathway. ${ }^{4,8}$ Although both operations share aortopulmonary amalgamation, arch reconstruction, and CPS, the patient groups possess distinct anatomy and physiology. In hybrid-treated patients, the pulmonary arteries have been banded resulting in restricted blood flow and a protected pulmonary vasculature. When the bands are removed, arterioplasty may be required to treat residual stenosis. ${ }^{8}$ On the contrary, late-presenters in this series have lived with unobstructed pulmonary blood flow and massive pulmonary overcirculation. Although these patients may realize some benefit from larger pulmonary arteries, they are disadvantaged by aggravated pulmonary vascular resistance.

Although the late timing of the Norwood is noteworthy, the early timing of the CPS in 5 patients younger than age 3 months may merit caution. Because studies have shown increased risk for early CPS, the optimal timing of surgery is reported as age 3 months or older. ${ }^{2}$ Similarly, hybrid proponents have recommended avoiding the comprehensive 
stage 2 operation before 3 months of age. ${ }^{9}$ Although the youngest patients in this series all survived, a BlalockTaussig shunt or Sano conduit may have been a better option.

In the end, the study provides an interesting look at an unusual scenario uncommon to most centers. This novel experience shows that a combined Norwood CPS is a viable option in late-presenting infants with increased pulmonary blood flow. Although the postoperative course may be rocky in this challenging situation, often requiring delayed sternal closure and pulmonary vasodilator therapy, intermediate survival appears comparable to the conventional sequence of staged operations. ${ }^{1,2,4}$

\section{References}

1. Ohye RG, Sleeper LA, Mahony L, Newburger JW, Pearson GD, Lu M, et al. Comparison of shunt types in the Norwood procedure for single-ventricle lesions. $N$ Engl J Med. 2010;362:1980-92.
2. Meza JM, Hickey E, McCrindle B, Blackstone E, Anderson B, Overman D, et al. The optimal timing of stage-2-palliation after the Norwood operation. Ann Thorac Surg. 2018;105:193-9.

3. Ismail MF, Elmahrouk AF, Arafat AA, Hamouda TE, Alshaikh BA, Shihata MS, et al. Evolution of the Norwood operation outcomes in patients with late presentation. J Thorac Cardiovasc Surg. 2020;159:1040-8.

4. Elmahrouk AF, Ismail MF, Arafat AA, Dohain AM, Edrees AM, Jamjomm AA, et al. Combined Norwood and cavopulmonary shunt as the firstpalliation in late presenters with hypoplastic left heartsyndrome and single-ventricle lesions. $J$ Thorac Cardiovasc Surg. 2022;163:1592-600.

5. Lai L, Laussen PC, Cua CL, Wessel DL, Costello JM, del Nido PJ, et al. Outcomes after bidirectional Glenn operation: Blalock-Taussig shunt versus right ventricleto-pulmonary artery conduit. Ann Thorac Surg. 2007;83:1768-73.

6. Adatia I, Atz AM, Wessel DL. Inhaled nitric oxide does not improve systemic oxygenation after bidirectional superior cavopulmonary anastomosis. J Thorac Cardiovasc Surg. 2005; 129:217-9.

7. Agarwal HS, Churchwell KB, Doyle TP, Christian KG, Drinkwater DC, Byrne DW, et al. Inhaled nitric oxide use in bidirectional Glenn anastomosis for elevated Glenn pressures. Ann Thorac Surg. 2006;81:1429-35.

8. Cua CL, McConnell PI, Meza JM, Hill KD, Zhang S, Hersey D, et al. Hybrid palliation: outcomes after the comprehensive stage 2 procedure. Ann Thorac Surg. 2018;105:1455-60.

9. Galantowicz M, Yates AR. Improved outcomes with the comprehensive stage 2 procedure after an initial hybrid stage 1. J Thorac Cardiovasc Surg. 2016;151:424-9.
See Article page 1592.

\section{Commentary: The right procedure for the right patient}

\author{
Maryam A. Al-Omair, MD, and Christoph Haller, MD
}

The Achilles' heel of single-ventricle palliation is the inherently unstable interstage circulation following both the Norwood procedure with systemic-to-pulmonary artery shunt or stage I hybrid palliation. This is reflected in the high mortality reported in patients with hypoplastic left heart syndrome before completion of a cavopulmonary shunt and the subsequent flattening of survival curves after stage II palliation. ${ }^{1}$ Primary construction of

\footnotetext{
From the Department of Cardiovascular Surgery, The Labatt Family Heart Centre, The Hospital for Sick Children, University of Toronto, Toronto, Ontario, Canada. Disclosures: The authors reported no conflicts of interest.

The Journal policy requires editors and reviewers to disclose conflicts of interest and to decline handling or reviewing manuscripts for which they may have a conflict of interest. The editors and reviewers of this article have no conflicts of interest.

Received for publication Nov 6, 2021; revisions received Nov 6, 2021; accepted for publication Nov 8, 2021; available ahead of print Nov 15, 2021.

Address for reprints: Christoph Haller, MD, Division of Cardiovascular Surgery, The Hospital for Sick Children, 555 University Ave, Toronto, Ontario M5G 1X8, Canada (E-mail: christoph.haller@sickkids.ca).

J Thorac Cardiovasc Surg 2022;163:1602-3

$0022-5223 / \$ 36.00$

Copyright (c) 2021 by The American Association for Thoracic Surgery

https://doi.org/10.1016/j.jtcvs.2021.11.018
}

Check for updates

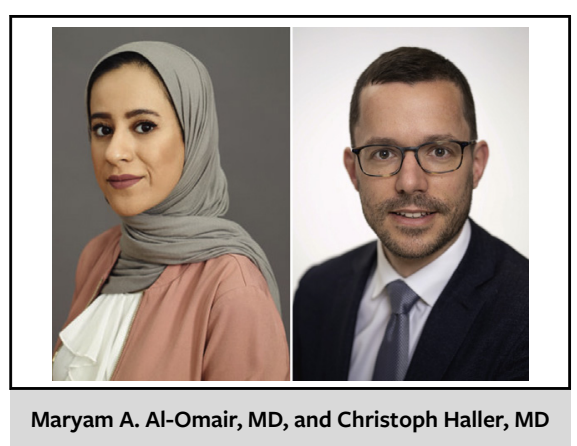

CENTRAL MESSAGE

Primary combined Norwood

cavopulmonary shunt proced-

ures are feasible, but only in a

highly selected group of patients.

a cavopulmonary anastomosis is impeded by high pulmonary vascular resistance (PVR) in neonates and young infants. Attempts to achieve a primary in-series circulation showed that this strategy was challenging, although not impossible..$^{2-4}$

Elmahrouk and colleagues ${ }^{5}$ report their experience with primary combined Norwood and cavopulmonary shunt 